\title{
nature
}

11 April 2002 Volume 416 Issue no 6881

\section{Rice must be perfectly cooked}

The draft genome sequences of Oryza sativa, published last week, are impressive achievements, but not the finished article. The public rice genome project more than ever deserves support.

$\mathrm{f}$ a base pair of DNA were a grain of rice, then a perfect sequence of the crop's genome would lay out 450 million grains end to end over more than 2,000 kilometres, with each grain correctly aligned and positioned. Assembling this sequence is the goal of the Japaneseled public International Rice Genome Sequencing Project (IRGSP), which is working on the japonica subspecies.

But the IRGSP is not the only game in town. The draft genomes of japonica by Syngenta, the Swiss-based agribiotech company, and of the indica subspecies by the Beijing Genomics Institute, published in Science last week, have identified almost all of the rice genes, and will be of immense value to plant breeders. And from the tone of some of last week's media coverage, one could be forgiven for thinking that the rice genome is now 'done' - leaving us standing on the brink of an agricultural revolution, and making the IRGSP redundant.

That would be an unfortunate perception. Funding for the IRGSP runs out in September, and it will need a further US\$10-15 million from its sponsors to finish the job. Policy-makers must understand that the Syngenta and Beijing sequences are rough drafts, with many gaps - more than 130,000, in the case of the Beijing draft - and entire chunks positioned or aligned incorrectly. While better organized than a rice stir-fry, they're still some way from that perfect chain of neatly aligned grains.

The newly proposed collaboration between the private- and public-sector projects (see page 573) means that the money required to finish the rice genome would represent excellent value — rather than completing the project by 2005 , it could be done by next year. And for the same price as is currently budgeted for finishing japonica, indica could be completed as well. The gains would come not just from sharing sequence data, but also from collaboration on strategies for assembling the sequenced fragments.

Having a sequence with gaps closed and errors corrected is important, for only then may it be possible to fully unravel the complex networks of genes and proteins that govern the crop's biochemistry and anatomy. Once in hand, moreover, this knowledge will transfer to other cereals, which, although they have much larger genomes, have similar genes arranged in much the same order. If the genetics of a particular biochemical pathway is understood in rice, this information can be used to isolate counterparts in other species. A finished rice genome, therefore, will boost efforts to genetically improve a variety of crops - including the attempt to increase yields of rice by giving it the photosynthetic efficiency of maize (see page 576).

But before we get carried away with dreams of feeding the world through transgenic technology, here's a shot of political and economic reality. The availability of the rice genome could make a major contribution to improving food security in the twenty-first century, but ridding the world of hunger and poverty will require more than higher crop yields. Indeed, the impact of the \$10-15 million needed to complete the rice genome needs to be considered in the context of the $\$ 1$ billion that rich countries spend daily on subsidies and other measures to protect their farming industries against exports from the developing world. Now there's food for thought.

\section{A climate for change}

\section{US climate research faces a revamp that may provide political leaders with better scientific information. Will they listen?}

$\mathrm{T}$ he threat posed by global warming was not a top priority for President George W. Bush at the time of his election and appears to be even less of one now. Since his administration announced its intention of walking away from the Kyoto Protocol more than a year ago, there's been little sign of a strategy to take its place. And the failure to re-nominate the respected atmospheric scientist Robert Watson as chair of the Intergovernmental Panel on Climate Change (see Nature 416, 251; 2002) has reinforced the impression of neglect.

Yet there is considerable concern about global warming among the US public. Recent news of the break-up of the Larsen B ice shelf on the Antarctic Peninsula, and the remarkably dry and mild winter that has just ended in North America, have added to this unease. As elsewhere in the world, however, the feeling that global warming is a real problem is held widely, but not particularly deeply. It is not yet an issue on which elections are won or lost.

The one thing that the Bush administration has promised to do is to strengthen the government's research programmes into the scientific understanding of the problem and the technological means available to address it. John Marburger, Bush's science adviser, is orchestrating a review of the US Global Climate Change Research Program, which was set up by Bush's father to coordinate this research (see page 571).

This attention is overdue. The programme office has never been powerful enough to coordinate the research activities of stridently independent agencies of the US government. As a result, for example, the United States' programme in climate modelling is much weaker than its considerable investment in climate change research should allow. Modellers need supercomputer capacity but lack access to it if they happen to work for the wrong agencies. No wonder that some are looking enviously at Japan's new Earth Simulator facility, and hoping they will be given time on the machine (see page 579 ).

Care must be taken to ensure that the new mechanisms erected by Marburger result in a balanced programme that is not obsessed with providing short-term answers and dubious technological fixes. But if this mistake is avoided, the revamp could give US climatechange research a new sense of direction, as well as a voice at the most senior levels of the administration. Whether anyone will listen, however, remains to be seen. 